\title{
Competência informacional como recurso emancipatório - estudo de caso com portadores de Diabetes Mellitus
}

\author{
Nadi Helena Presser \\ Universidade Federal de Pernambuco - Brasil
}

CASE REPORT

\begin{abstract}
Resumo
A competência informacional é a aptidão de uma pessoa de mobilizar conhecimentos, habilidades e atitudes para tomar decisões, com base em informações. No âmbito da saúde, é a tomada de iniciativa do paciente no processo de busca e uso de informações relativas aos problemas suscitados por determinada patologia, como recurso de emancipação e desenvolvimento da sua cidadania. Este artigo é uma reflexão sobre o arcabouço teórico e metodológico da competência informacional no contexto dos portadores de Diabetes Mellitus (DM) dos pacientes atendidos no Centro Médico Senador José Ermírio de Moraes (CMSJEM), localizado no Município de Recife, Estado de Pernambuco (PE), Brasil. Do ponto de vista da forma de abordagem se caracteriza uma pesquisa qualitativa e quantitativa, na qual os dados primários foram coletados por meio de entrevistas semiestruturadas. Embora o tratamento do DM prescreva considerável autocuidado devido aos agravos decorrentes de suas complicações, os resultados deste estudo demonstram que poucos, entre os pacientes pesquisados, apresentam competências em informação que apontem potenciais emancipatórios.
\end{abstract}

Palavras-chave

Competência informacional ; Recurso emancipatório ; Diabetes mellitus ; Saúde ; Recife ; Brasil

Information literacy as emancipatory resource - case study of patients with Diabetes Mellitus

\begin{abstract}
The information literacy is the ability of a person to mobilize knowledge, skills and attitudes in order to undertake decisions based on information. In the health field, such competence is the patient's initiative taking in the process of information searching and use, relative to problems caused by certain pathology, as an emancipatory resource and development of their citizenship. This article is a reflection on the theoretical and methodological framework of information literacy in the context of patients with Diabetes Mellitus (DM) treated at the Medical Center Senador José Ermírio de Moraes (MCSJEM), located in the city of Recife, Pernambuco (PE) state, Brazil. From the viewpoint of the selected approach method, the research is qualitatively and quantitatively characterized, in which the primary data were collected by means of semi-structured interviews. Although the treatment of DM requires considerable self-care, due to eventual injuries resulting from complications, the results of this study demonstrate that among the patients surveyed, few of them show abilitys with information that indicate emancipatory capacity.
\end{abstract}

Keywords

Information literacy ; Emancipatory resource ; Diabetes mellitus ; Health ; Recife ; Brasil 


\section{Introdução}

A information literacy surge como uma proposta de solução para os problemas informacionais das pessoas. Propõe uma relação construtiva entre pessoas e informações, desde a identificação de uma necessidade informacional, passando pelo domínio das tecnologias de informação e dos conteúdos e, principalmente, no exercício de utilizar o conteúdo informacional para tomada de decisão na vida profissional, nas relações sociais e na vida privada.

Traduzida no Brasil como competência informacional, na década de 70, Zurkowski (1974) já a apontava como uma alternativa para as pessoas aplicarem os recursos informacionais para seu trabalho e para os seus diversos problemas da vida cotidiana. Posteriormente, um relatório da American Library Association - ALA imprime considerável evolução ao conceito de competência informacional ao definir que

Para ser competente em informação uma pessoa deve ser capaz de reconhecer quando uma informação é necessária e expressar essa necessidade para, posteriormente, desenvolver habilidades para localizar, avaliar e usar efetivamente a informação (ALA, 1989, p. 1).

Compreendida como um processo educativo ao longo da vida das pessoas (Kuhlthau, 1987), a competência informacional consolida-se como um tema que se expande por todo o mundo, principalmente entre os bibliotecários.

Dudziak (2003) faz um apanhado da história do surgimento da expressão information literacy e, a partir da análise da evolução do conceito e reconhecendo-a como um aprendizado ao longo da vida, define competência informacional:

[...] como o processo contínuo de internalização de fundamentos conceituais, atitudinais e de habilidades necessários à compreensão e interação permanente com o universo informacional e sua dinâmica, de modo a proporcionar um aprendizado ao longo da vida. (Dudziak, 2003, p. 28).

A partir disso, depreende-se que o desenvolvimento da competência está imbricado no desenvolvimento de recursos que possam ser mobilizados, em um dado contexto. Competência informacional, nessa perspectiva, não trata apenas do processo de busca de informações, mas do uso que se faz dela para tomar decisões e resolver problemas. Tem sido objeto de estudos de diferentes usuários e contextos sociais, tendo a informação como indutora da cidadania e da autonomia e propulsora dos potenciais emancipatórios das pessoas.

Assim, o propósito deste trabalho foi investigar como os portadores de diabetes interagem com a informação e desenvolvem sua competência informacional, de maneira que possam alcançar essa emancipação, ampliando seus conhecimentos a respeito da patologia, para monitorar seu tratamento ao longo da vida.

Em um sentido específico, este estudo examinou os mecanismos pelos quais os portadores de diabetes identificam necessidades e buscam informações sobre o tratamento e monitoramento da doença e até que ponto a informação influencia seus comportamentos e impulsiona mudanças no estilo de vida dessas pessoas.

Do ponto de vista da forma de abordagem do estudo, optou-se por uma pesquisa qualitativa e quantitativa (Martins\&Theóphilo, 2009) para descobrir e entender a complexidade e a interação de elementos relacionados à competência informacional.

O objeto empírico desta pesquisa estendeu sua ação no ambiente do CMSJEM, serviço que compõe a rede municipal de saúde e que presta assistência especializada em oftalmologia, diabetes e hipertensão arterial, localizado no Município de Recife, no Estado de Pernambuco, pelo fato de que a tomada de consciência, o autocuidado e o monitoramento da doença são condições sine qua non para preservar a qualidade de vida dessas pessoas. Mensalmente, o Centro Médico realiza consultas com cerca de 240 pacientes de diabetes.

Segundo o Portal do Banco de Saúde (2011), o Diabetes Mellitus (DM) é uma doença metabólica caracterizada por um aumento anormal do acúcar ou glicose no sangue. Quando não tratada adequadamente podem ocorrer complicações como insuficiência renal, problemas na visão, dentre outros problemas. A obesidade, má alimentação e o sedentarismo figuram entre os principais fatores de risco.

Por caracterizar-se como uma pesquisa envolvendo seres humanos, antes da aplicação do questionário foram adotadas as providências relativas às permissões e autorizações especiais de caráter ético e legal, necessárias à execução do projeto, entre elas a aprovação pelo Comitê de Ética. 
Para examinar os mecanismos pelos quais os portadores de diabetes identificam necessidades e buscam informações e até que ponto a informação influencia mudanças no estilo de vida dessas pessoas, foram pesquisados pacientes adultos, em função da sua maturidade no processo de busca de informações.

Foi adotada amostra não probabilística e com características de amostragem consecutiva e de amostragem conveniente (Luna Filho, 1998). O instrumento de coleta de dados constitui-se de um formulário de entrevista, semiestruturado, com perguntas abertas e outras de múltipla escolha, aplicado nos meses de maio e junho de 2012. A coleta de dados foi realizada por dois pesquisadores do grupo de pesquisa Prospecção e Práxis em Gestão da Informação que, nos dias de consulta médica dos pacientes, realizavam a entrevista pessoalmente, após explicação acerca dos objetivos do estudo. A escolha dos entrevistados deu-se de maneira aleatória, sem critérios, considerando apenas a disponibilidade dos pacientes em responder às questões.

Inicialmente, no mês de abril, foram entrevistados 10 pacientes no pré-teste, permitindo o ajuste dos questionários. Em seguida, entrevistaram-se 60 pacientes por meio da assinatura do Termo de Consentimento Livre e Esclarecido. Os objetivos da pesquisa orientaram a coleta e análise dos dados e o foco do estudo.

A pesquisa evidenciou que ${ }^{1}$ :

a) Quanto à faixa etária:

- $50 \%$ deles possuíam idade superior a 60 anos;

- $44 \%$ possuíam idade entre 40 e 60 anos.

b) Em relação à renda familiar:

- $41 \%$ ganhavam até um salário mínimo;

- $\quad 27 \%$ recebiam entre um e dois salários mínimos;

- $\quad 23 \%$ recebiam entre dois e três salários mínimos;

- $\quad 7 \%$ recebiam mais de três salários mínimos.

c) Quanto à escolaridade:

- $5 \%$ eram analfabetos;

- $\quad 56 \%$ possuíam ensino fundamental;

- $\quad 29 \%$ deles possuíam ensino médio;

- $\quad 14 \%$ possuíam nível superior.

\section{Competência informacional - características e conceitos}

O termo "competência" tem recebido vários significados ao longo do tempo nas diversas áreas. Para o educador Perrenoud (2001), um dos primeiros pesquisadores da área da educação a estudar o tema, competência é a faculdade de mobilizar um conjunto de recursos cognitivos (saberes, capacidades, informações etc.) para solucionar com pertinência e eficácia uma série de situações. O termo se consolidou e, segundo o dicionário de verbetes em educação de Menezes e Santos (2002), competência é um conjunto de conhecimentos (saberes), habilidades (saber fazer) e atitudes (saber ser).

Na área da Ciência da Informação (Cl), o termo ganhou destaque nos debates atuais, pois faz referência aos conhecimentos, habilidades e atitudes que precisam ser mobilizados no universo informacional (Pontes Júnior \& Tálamo, 2009; Guedes \& Farias, 2007; Duarte, 2007; Miranda, 2006; Belluzzo 2005a; Dudziak, 2003; Doyle, 1992). Assim, para a maioria desses autores, competente em informação é aquele que identifica, sintetiza e relaciona informações para compreender fenômenos; é a pessoa que julga, avalia, pondera e toma decisões com base em informações, de forma conveniente e adequada.

Partindo da conexão teórica entre necessidades informacionais e competência em informação, conforme estudado por Miranda (2006), o reconhecimento de necessidades de informação pode corresponder, na prática, ao desenvolvimento de competências informacionais de uma pessoa para atendê-las e, se possível, com seus próprios meios.

Isso pressupõe que as relações que se estabelecem entre o desenvolvimento de competências específicas ligadas a um determinado tema e as necessidades de informação são sobrepostas umas às outras: ao mesmo tempo em que 
um usuário busca informação, ele amplia suas necessidades informacionais à medida que novas demandas vão aparecendo. Assim, a necessidade de informação é "[...] evolutiva e extensiva, porque muda com o tempo sob o efeito da exposição às diferentes informações iniciais e é produzida dinamicamente gerando novas necessidades." (Miranda, 2006, p. 102).

Dentre as habilidades que formam a competência informacional, alguns autores destacam o uso da tecnologia da informação como um instrumento que potencializa o acesso à informação, que, por seu turno, determina novos comportamentos, atitudes e práticas no processo de busca de informação. Seguramente, os cidadãos com acesso às tecnologias informacionais têm melhores condições de tomar decisões e resolver problemas com base em informação.

Corroborando com esse ponto de vista, Pontes Júnior e Tálamo (2009) consideram a ausência de competência informacional como um dos fatores do processo de exclusão digital. Carvalho (2003), por sua vez, classifica como excluídos digitais todas as pessoas que sentem dificuldade em operar determinados tipos de máquinas digitais, independente de sua posição socioeconômica. Uma das causas, segundo ele, é a dificuldade operativa de máquinas sofisticadas, impossibilitando às pessoas o uso delas, por falta de treinamento, habilidade ou incapacidade física. Todavia, Carvalho (2003) evidencia que a falta de interação entre homem e máquina pode ser minimizada por meio de processos de capacitação em competência informacional.

Porém, não se trata apenas de usar tecnologias de informação. O acesso à informação a partir de um suporte digital constitui apenas uma das muitas habilidades requeridas. Tomaremos aqui as observações de Takahashi (2000):

Educar em uma sociedade da informação significa muito mais que treinar as pessoas para o uso das tecnologias de informação e conhecimento: trata-se de investir na criação de competências suficientemente amplas que Ihes permitam ter decisões fundamentais no conhecimento, operar com fluência os novos meios e ferramentas em seu trabalho, bem como aplicá-los criativamente nas novas mídias, seja em usos simples e rotineiros, seja em aplicações mais sofisticadas. (Takahashi, 2000, p.3).

Trata-se, portanto, de fazer uso crítico da informação para tomar decisões e resolver problemas, com autonomia. Ter autonomia pressupõe a capacidade de um usuário da informação de atender às suas próprias necessidades de informação por meio de um aprendizado contínuo, ativo e independente, no qual as tecnologias de comunicação assumem papel considerável.

Vislumbrando as várias acepções do termo "competência informacional" desenvolvidas no campo da Cl, muitos pesquisadores e instituições formularam um conjunto de competências e indicadores para figurar como símbolo de competência informacional de uma pessoa, com destaque para as competências dos bibliotecários.

a) Doyle (1992) formulou sete indicadores que refletem o grau de competência informacional de uma pessoa.

b) Dudziak (2003) elaborou seis critérios, denominados por ela como objetivos, para determinar o grau de competência informacional de uma pessoa, que, uma vez desenvolvidos, forneceriam um nível de autonomia para um indivíduo ou um grupo para lidar com o universo informacional.

c) A American Library Association definiu um conjunto de indicadores para representar o nível de competência dos estudantes, os quais foram organizados e publicados por Duarte (2007).

d) O projeto chinês Information Literacy Competency Standards for Higher Education, apresentado por Xiaomu, Ping, Mengli, e Du Weichun (2008) descreve os padrões e identifica indicadores de competência informacional na educação superior na China.

e) Pontes Júnior e Tálamo (2009) apresentam os "Sete Pilares", que definiriam o escopo da competência informacional, apresentados em um documento aprovado durante a "Conference of National and University Libraries", realizada em Londres em 1999. O modelo, concebido para capacitar alunos de graduação e pósgraduação de bibliotecas universitárias mostra, segundo esses autores, o processo evolutivo das competências informacionais na busca, recuperação e uso da informação.

A mensagem subjacente nas proposições desses autores é que a competência informacional se manifesta na capacidade de reconhecer uma necessidade de informação, de identificar, localizar, avaliar, organizar e utilizar informações tanto para resolver um determinado problema como para o simples prazer de aprender ao longo da vida. 


\section{O contexto do Diabetes como um quadro de referência na formação da competência informacional como recurso emancipatório}

Associadas ao contexto do DM, as reflexões acima expostas colocam ênfase no desenvolvimento da competência informacional como prática emancipatória, fazendo relação com Bottomore (1997), que associa o conceito de emancipação com a supressão dos obstáculos ao desenvolvimento das possibilidades humanas. Na mesma perspectiva, na visão de Freire (1989), a emancipação consiste num fazer histórico permeado por desafios e possibilidades e se efetivará na vivência da condição humana de ser protagonista de sua história.

Para esses autores, o domínio emancipatório significa exercer a autoemancipação. Portanto, tomar a competência informacional a serviço do processo de emancipação humana, no âmbito desta pesquisa, passa a ser ação do próprio portador da doença. Essa emancipação não acontecerá por concessão, mas será uma conquista efetiva dos portadores da patologia, demandando um processo de aprendizagem ao longo da vida, em constante construção.

Os desafios dos diabéticos, nessa perspectiva, são tomados em um contexto histórico e social, onde se observa a emergência de diferentes atores e fontes de informação, no qual a proposição fundamental da competência informacional é estimular processos que promovam a emancipação individual e coletiva de todos. Daí a necessidade de trazer à tona o debate e uma proposta de competências informacionais polarizadas pelo saber, saber fazer e ser. Uma vez desenvolvidas, devem promover as potencialidades humanas dos portadores da doença e fortalecer, pela aprendizagem responsável, a sua autonomia frente a si mesmo e aos outros.

Os especialistas da área advertem que um tratamento médico adequado, com medicamentos, dietas, controle do peso e atividades físicas, é de suma importância para evitar complicações e melhorar a qualidade de vida de pacientes. Como estratégias de promoção da saúde e de prevenção de complicações, a Organização Mundial da Saúde (2003) propõe aliar às intervenções dos profissionais de saúde especializados atividades educativas visando ao autocuidado dos portadores.

Segundo a Sociedade Brasileira de Diabetes (2007), o DM é a elevação da glicose no sangue. Os alimentos sofrem digestão no intestino e se transformam em glicose (açúcar), que é absorvida para o sangue e usada pelos tecidos como energia. A sua utilização depende da presença de insulina, uma substância produzida nas células do pâncreas. Quando a glicose não é bem utilizada pelo organismo, ela se eleva no sangue, causando a hiperglicemia. Dependendo da causa, o diabetes pode ser classificado em três tipos: diabetes tipo 1, diabetes tipo 2 e diabetes gestacional.

O diabetes tipo 1 é mais comum em crianças, adolescentes ou adultos jovens. O diabetes tipo 2 corresponde a 90\% dos casos, ocorre geralmente em pessoas obesas com mais de 40 anos de idade, embora na atualidade se veja com maior frequência em jovens, em virtude de maus hábitos alimentares, sedentarismo e estresse da vida urbana. O diabetes gestacional se caracteriza pela presença de glicose elevada no sangue durante a gravidez, que geralmente se normaliza após o parto.

A Sociedade Brasileira de Diabetes (2007) reconhece que, na sua grande maioria, as intervenções dos profissionais especializados concentram-se no controle glicêmico para evitar ou minimizar tais complicações. Entretanto, Torres, Souza e Lima (2011) evidenciam que o controle glicêmico depende da mudança de hábitos, muitas vezes arraigados culturalmente e associados a questões subjetivas relacionadas ao modo de vida das pessoas. Por tudo isso, o tratamento do DM deve incluir atividades de cunho educativo voltadas à promoção do autocuidado para apoiar os portadores do DM na condução dos desafios inerentes ao seu tratamento, diante das demandas impostas pela patologia.

Expressa-se, assim, um fenômeno em que a competência informacional se manifesta na tomada de iniciativa do paciente, na sua autonomia e capacidade de saber agir em um contexto no qual as circunstâncias da patologia exigem a adoção de mudanças individuais relacionadas ao estilo de vida, mobilizando a pessoa a buscar e usar informações, ao longo da vida, em um processo emancipatório. 
Entretanto, esse processo não pode ser separado de seu contexto social integrado pelas diversas especialidades médicas, os profissionais de áreas complementares, tais como enfermeiros, fisioterapeutas, psicólogos, nutricionaistas, profissionais de educação física, assistentes sociais; e o próprio paciente e seus familiares e cuidadores. Ações de caráter social e coletivo são conduzidas por essas equipes muldisciplinares formadas por diferentes profissionais, na perspectiva de uma assistência ampla que promova a redução dos riscos das complicações da doença.

No CMSJEM, segundo Oliveira (2011), destaca-se o Programa de Educação em Diabetes (PED), que vem sendo colocado em prática desde o primeiro ano de sua fundação. Esse programa fornece suporte ao paciente e a sua família na condução do tratamento e na prevenção das principais complicações, por meio da promoção de atividades educativas visando mudanças de atitudes dos pacientes. Outro programa, criado em 2004 tem como objetivo a reabilitação cardiovascular, pulmonar e metabólica dos portadores da doença, por meio da promoção de atividades físicas. Os diabéticos recebem orientação sobre a maneira correta de realizar os exercícios recomendados pelos médicos, incorporando atividades neuromusculares, aeróbicas e socioculturais, fisioterapia cardiorrespiratória e ainda avaliação e orientação nutricional. O suporte de uma equipe de psicólogos, professores de educação física e nutricionistas e um serviço especializado em odontologia para diabéticos, cujos atendimentos estão disponíveis para todos os pacientes interessados traduz outra ação desenvolvida pelo CMSJEM.

Em uma esfera mais ampla, a Sociedade Brasileira de Diabetes (SBD), filiada à International Diabetes Federation (IDF), é uma instituição referência em nível nacional e internacional e contribui para a prevenção e tratamento do diabetes em três fases: (a) Produção e disseminação de conhecimento; (b) Conscientização da população; (c) Colaboração com o Estado na elaboração de políticas públicas. Para garantir tal contribuição, a SBD realiza a cada dois anos um congresso nacional para atualização científica e educacional, publica periodicamente a "Diabetes - a revista da SBD", revista destinada aos seus associados para a divulgação dos trabalhos desenvolvidos, e, desde 1997, desenvolve o Projeto Diabetes Online, através da homepage da SBD, constituída como um centro de informação, possibilitando acessar informações sobre prevenção, tratamento, estudos e notícias sobre a patologia.

A competência informacional, nesta perspectiva, é a capacidade dos portadores de DM de mobilizar esse conjunto de recursos colocados à sua disposição, a fim de enfrentar com eficácia as mais variadas situações reais impostas pela patologia. O seu desenvolvimento configura-se e se consolida em um processo dinâmico que se modifica para incorporar novos conhecimentos, habilidades e atitudes à medida que as pessoas se emancipam. Por isso, passa pela integração e pela aplicação sinérgica desses recursos nas diferentes situações, como um aprendizado ao longo da vida.

Nessa abordagem, além de reunir conhecimentos, habilidades e atitudes, como propõe Miranda (2006), a competência informacional abrange a dimensão social do processo informacional, associada à noção de cidadania e autonomia das pessoas envolvidas. As ligações que se estabelecem entre conhecimento, habilidades e atitudes determinam mudanças sociais, o que pressupõe "[...] a própria essência do aprendizado como fenômeno social." (Dudziak, 2003, p. 30).

Assim, a competência informacional expande sua esfera para a formação de pessoas autônomas e emancipadas, capazes de aplicar meios diferenciados de busca de informações adequadas a suas necessidades específicas. Não obstante, essa concepção de competência aproxima-se, assim, de uma perspectiva social, na medida em que busca a construção e a mobilização de conhecimentos, habilidades, atitudes e valores tanto no âmbito individual, quanto na dimensão social: as competências informacionais são construídas ao longo da trajetória da vida do paciente, o qual partilha experiências e práticas coletivas, e que estão condicionadas pelo contexto econômico, social e político, sendo expressão de relações sociais entre os interesses dos diversos atores envolvidos no processo.

Baseando-se em Courtright (2007), pressupõe-se o domínio do DM configurado em um contexto socialmente construído, no qual os usuários informacionais são formados ao mesmo tempo em que formam o contexto. O portador da doença e os profissionais especializados vão se transformando nas suas estruturas e atitudes e simultaneamente transformam essa realidade. Assim, promovem-se e valorizam-se outros valores, novas atitudes e comportamentos no âmbito individual e social. 
A emancipação, nessa abordagem, não se refere apenas ao indivíduo como entidade isolada, mas fundamentalmente como um ser social (Adorno, 1995), e se funda na vontade particular de cada um em se desenvolver. A partir disso, a possibilidade de levar cada um a responsabilizar-se pelo seu aprendizado ao longo da vida sobre determinada patologia converte-se numa forma particular do desenvolvimento da emancipação. Entretanto, se a emancipação é a formação para a autonomia, ela só pode ser bem-sucedida se for um processo coletivo, onde a mudança individual é precondição da mudança social.

Nessa mesma linha, Belluzzo (2005a) define a competência, primeiro, em uma dimensão relacionada ao domínio de saberes e habilidades que permite a uma pessoa fazer uma intervenção prática na realidade, e, segundo, numa dimensão que diz respeito à visão crítica do alcance das ações e ao compromisso com as necessidades mais concretas que emergem e caracterizam o atual contexto social. Da mesma forma, Reece (2007) mostra o significado crítico e emancipatório da competência informacional aplicado ao domínio da informação.

Trata-se, portanto, de um processo que diz respeito a um conjunto de atividades de busca e uso de informações em que o usuário não necessariamente procede através de uma série de passos sistemáticos, mas persegue e conduz a busca à medida que as informações surgem e à medida que se configuram mudanças na sua base de conhecimento. Esse processo pode variar de acordo com o seu conhecimento prévio, seus problemas, seu estado cognitivo, o contexto social em que está inserido e a disponibilidade de um ambiente informacional. Considera-se, ainda, que necessidades podem ou não ser sentidas e as informações recuperadas podem ou não vir a ser utilizadas, conforme este estudo apontou.

\section{Os desafios na formação da competência informacional - considerações sobre os resultados da pesquisa}

Embora o tratamento do DM prescreva considerável autocuidado devido aos riscos de complicações da doença, os resultados deste estudo demonstram que poucos, entre os pacientes pesquisados, apresentavam competência em informação que apontasse potenciais emancipatórios, como evidenciado na Tabela 1.

A Tabela 1 reflete o estágio dos portadores de DM do CSMSJEM, nos processos de identificação das necessidades, seleção de fontes de informação, busca e uso de informação. Se o controle da doença diminui o risco de suas complicações, então muitos pacientes apresentam probalidades de aumentar seus problemas, devido à falta de informações e cuidado com o tratamento.

Configura-se uma realidade na qual a educação e a participação do paciente ainda são incipientes e justifica-se um estudo mais amplo para identificar a realidade social subjacente relacionada aos aspectos psicossociais, educacionais e culturais, como costumes, crenças e religiões, não apenas para entender esses aspectos, mas para incluí-los no processo.

Uma abordagem sobre fatores sociais e culturais no processo informacional é a teoria da pobreza informacional de Chatman (1996). O que está subentendido na teoria dessa pesquisadora é a diferença entre incluídos (insiders) e excluídos (outsiders) com relação aos estudos informacionais e o que isso significa à luz da percepção, aquisição e uso da informação. Um mundo de pobreza informacional é aquele em que uma pessoa não deseja ou não está apta a resolver um problema crítico ou uma preocupação. 


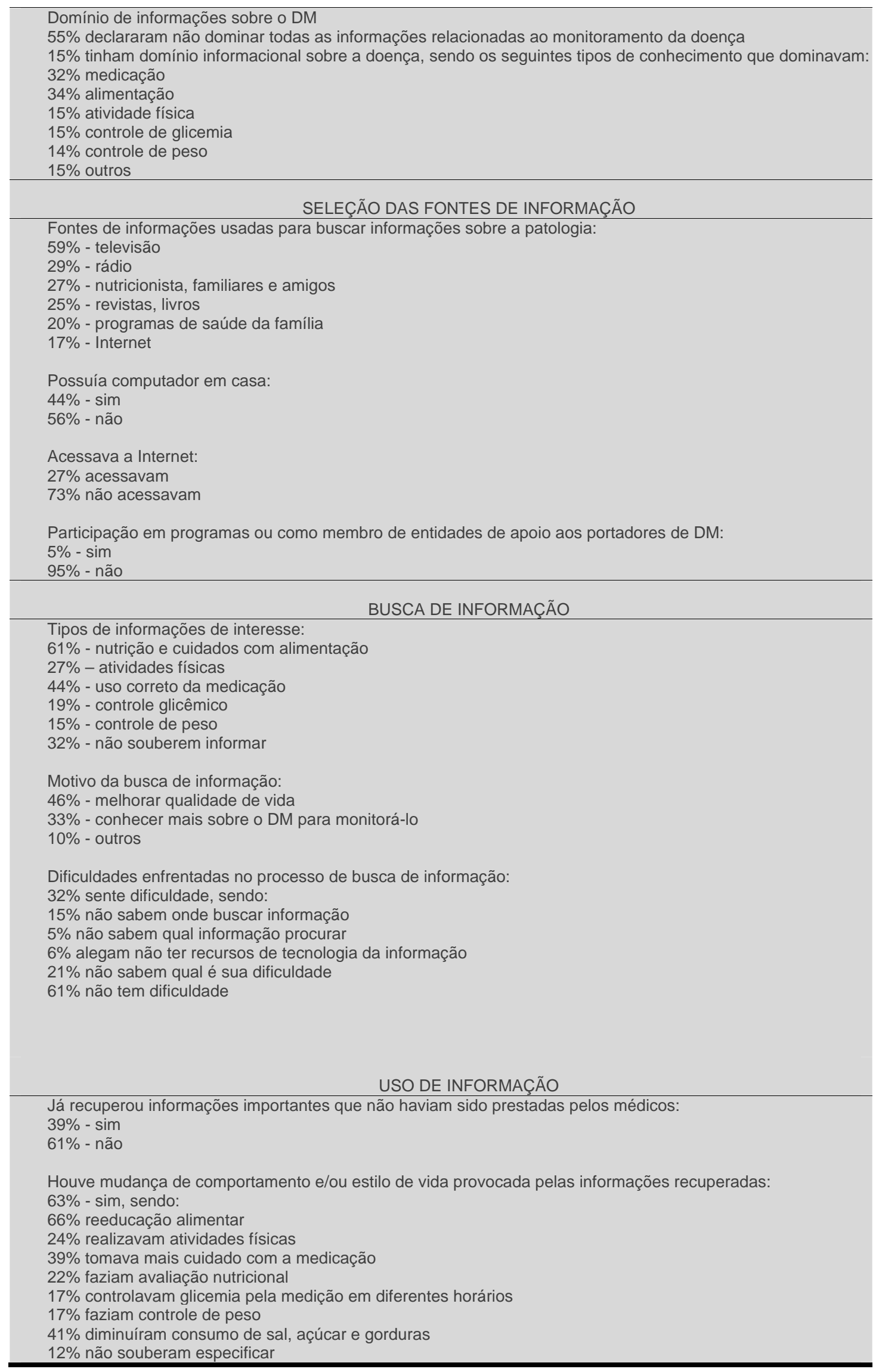


Fonte: Tabela elaborada pelos próprios autores, com base nas respostas dos entrevistados

De acordo com Chatman (1996), as pessoas vivem em um mundo empobrecido quando elas escolhem ignorar informação apesar de saberem que ela pode ser de ajuda para lidar com suas preocupações e problemas diários. Sua pesquisa revelou situações nas quais as pessoas sabem que existem informações importantes, relevantes e potencialmente úteis, mas altos custos sociais as induzem a ignorá-las.

Certamente, o desenvolvimento e o grau de competência informacional não estão separados das inerentes condições socioculturais e econômicas do contexto onde o fenômeno ocorre, conforme refletido no perfil socioeconômico dos entrevistados (ver escolaridade, renda familiar e faixa etária dos entrevistados na introdução deste artigo), com variações conforme as características das distintas formações sociais dos portadores de DM entrevistados.

Os conhecimentos e habilidades são desenvolvidos a partir de determinadas atitudes e caracterizam-se, portanto, como elementos constitutivos das competências, que combinados adequadamente formam a competência informacional de um portador de DM. As habilidades, relacionadas ao saber fazer, por exemplo, são inseparáveis da ação, mas exigem domínio de conhecimentos e emprego de atitudes adequadas à sua realização. As atitudes, por sua vez, refletem a predisposição de uma pessoa de agir e reagir, ou uma forma de proceder em função da doença, destacando-se a disciplina, autonomia e responsabilidade pelo seu próprio aprendizado. Conforme a pesquisa apontou (ver Tabela 1), 55\% dos entrevistados declararam não dominar todas as informações sobre sua doença e somente $5 \%$ participam de programas ou como membros de entidades de apoio aos portadores de DM. Há que se considerar que essas entidades e programas são criados essencialmente para orientar os portadores da patologia no cuidado e monitoramento da doença, independente de sua classe social.

Esse tipo de competência não visa à aquisição de um repertório especializado de saberes sobre DM, domínio este específico dos médicos e enfermeiros e outros profissionais da saúde, mas antes o domínio do conhecimento básico e necessário ao monitoramento da patologia, tanto no âmbito da medicação, como da alimentação e atividades físicas adequadas, possibilitando fazer escolhas mais conscientes e determinar o curso de suas vidas.

Ademais, é perceptível a desigualdade no acesso à informação: 56\% declararam não possuir computador e 73\% não acessavam a Internet. Apesar da importância atribuída à faceta democratizante da Internet, são necessários pré-requisitos socioeconômicos e tecnoculturais para acessá-la, condições ausentes especialmente nos grupos excluídos e vulneráveis da sociedade e que mais se beneficiariam das práticas emancipatórias. A pesquisa não examinou a possibilidade de haver recusa no uso de tecnologias informacionais, mas as deficiências em termos de acesso à infraestrutura de informática e à Web são evidenciadas nos grupos sociais mais desfavorecidos em termos socioeconômicos. Portanto, são mais desafiadores os problemas de aproximar indivíduos desinformatizados às tecnologias da comunicação na perspectiva de desenvolver sua competência informacional.

\section{Conclusão, limites da pesquisa e recomendações}

Se a competência informacional é a aptidão de uma pessoa de mobilizar conhecimentos, habilidades e atitudes para tomar decisões, com base em informações, então explorar aspectos relacionados ao desenvolvimento da competência informacional dos portadores de DM deve oferecer subsídios para a reflexão das particularidades que interferem na sua autonomia e emancipação.

Tendo em vista que a pesquisa aponta que 95\% dos entrevistados não participavam de nenhum programa de apoio aos diabéticos e que 58\% declararam não ter ou raramente sentir necessidade de informações sobre sua doença, parece que a falta de informações e esclarecimentos a respeito do problema pode gerar insegurança quanto à sua capacidade para cuidar e monitorar a situação e, certamente, deve estar associada às atitudes nas mudanças do estilo de vida, necessárias ao tratamento.

Todavia, os resultados deste estudo apontam o estágio em que os portadores de DM se encontravam, nos processos de construção do conhecimento sobre a patologia, mas não explicam suficientemente como os aspectos socioculturais e econômicos contribuem para decisões bem informadas. 
Como reflexões sobre questões dessa ordem, ainda que de modo preliminar, cabe indagar: Quais as implicações dos múltiplos aspectos do complexo campo da competência informacional nas intersecções saúde, autocuidado e emancipação, parcialmente representados nos resultados desta pesquisa? Como é possível se orientar diante de diversas e eventualmente conflituosas perspectivas que se originam das inter-relações entre portadores da doença, familiares, entidades e equipe multidisciplinar de profissionais responsáveis pela assistência de variados tipos, e os portais e bases de dados, ambos disponibilizando informações com distintos níveis de linguagem médica especializada e qualidade? Quais são as implicações de se considerar, ou não considerar, o contexto social dos usuários na construção de portais e demais sistemas informacionais? Como fazer frente à ideia de emancipação diante das dimensões socioculturais do autocuidado?

Sem a pretensão de esgotar ou até mesmo concluir este debate, denota-se que a competência informacional nos cuidados com a saúde consiste em um estado de busca e uso de informação, em que os aspectos sociais, culturais e econômicos presentes restringem ou favorecem a emancipação. Assim, os resultados desta pesquisa podem estar associados aos valores e normas apreendidos e sustentados pelos membros de um grupo social como discute Chatman (1996), definindo as informações que são legitimadas para buscar e apropriadas para compartilhar.

Decorre disso que, ao mesmo tempo em que apontam as limitações desta pesquisa no sentido do não aprofundamento das dimensões sociais, também recomendam novos estudos no âmbito do exame das mediações do contexto social da competência informacional. As ideias e crenças do portador da DM relacionadas ao conceito de saúde e doença podem definir o modo e a capacidade de cada indivíduo de elaborar mecanismos para o enfrentamento do problema. 


\section{Referências}

Adorno, T. W. (1995). Educação e Emancipação. Rio de Janeiro: Paz e Terra.

American Library Association. (1989). Report of the Presidential Committee on infomation literacy: Final Report. Retrieved from http://www.ala.org/acrl/nili/ilit 1st.html

Belluzzo, R. C. B. (2005a, July). Contribuição ao desenvolvimento da competência em informação em bibliotecas públicas paulistas: uma experiência com apoio de oficinas de trabalho. Postersessionpresentedatthe Congresso Brasileiro de Bibioteconomia, Documentação e Ciência da Informação. Curitiba, PR.

Bottomore, T. Dicionário do pensamento marxista. (1997). Rio de Janeiro: Zahar.

Capurro, R. Epistemologia y ciencia de la información. (2003, November). PostersessionpresentedattheEncontro Nacional de Pesquisa em Ciência da Informação. Belo Horizonte.

Carvalho, J. O. F. (2003, September/December). O papel da interação humano-computador na inclusão digital. Transinformação, 15 (edição especial), 75-89.

Chatman, E. A. (1996). The Impoverished Life-World of Outsiders.Journal of the American Society for Information Science, 47(3), 193-206.

Courtright, C. (2007). Context in Information Behavior Research.Annual Review of Information Science and Technology, 41 (1),273306. doi10.1002/aris.2007.1440410113

Doyle, C. (1992, June 24). Outcome Measures for Information Literacy Within the National Education Goals of 1990: Final Report of the National Forum on Information Literacy. Summary of Findings. Retrieved from http://www.eric.ed.gov/PDFS/ED351033.pdf

Duarte, A. B. S. (2007). Informação, sociedade e inclusão digital. In Reis, A. S. (org.). Informação, cultura e sociedade: interlocuções e perspectivas. Belo Horizonte: Novatus.

Dudziak, E. A. (2003, January/April).Informationliteracy: princípios, filosofia e prática. Ciência da Informação, 32 (1),23-35.

Freire, P. (1989). Educação como prática de liberdade. Rio de Janeiro: Paz e Terra.

Guedes, C. A.,\&Farias, G. B. (2007, January/June).Informationliteracy: uma análise nas bibliotecas escolares da rede privada em Natal/RN. Revista Digital de Biblioteconomia e Ciência da Informação, 4(2),110-133.

Kuhlthau, C. C. (1987). Information skills an information society: a review of research.Syracuse, NY: ERIC Clearinghouse on information resources.

LunaFilho, B. (1998). Sequência básica na elaboração de protocolos de pesquisa. Arquivos Brasileiros de Cardiologia,71 (6), $735-$ 740. Retrieved from http://www. scielo.br/pdf/abc/v71n6/a01v71n6.pdf

Martins, G. A., \&Theóphilo, C. R. (2009).Metodologia da investigação científica para ciências sociais aplicadas (2nd ed.). São Paulo: Atlas.

Menezes, E. T. de, \&Santos, T. H. dos. (2002). Competência (verbete). Dicionário Interativo da Educação Brasileira- EducaBrasil. São Paulo: Midiamix Editora. Retrieved from http://www.educabrasil.com.br/eb/dic/dicionario.asp?id=56

Miranda, S. (2006, September/December). Como as necessidades de informação podem se relacionar com as competências informacionais. Ciência da Informação, 35 (3),99-114.

Organização Mundial da Saúde. (2003). Cuidados inovadores para condições crônicas: componentes estruturais de ação: relatório mundial. Brasília: Organização Mundial da Saúde.Retrieved from http://www.opas.org.br/sistema/arquivos/Manual final.pdf

Oliveira, M. S. (2011). Dilemas da integralidade: o olhar sobre um serviço especializado na assistência em diabetes. Recife, PE: Universidade Federal de Pernambuco.

Perrenoud, P. (2001). Formando professores profissionais: Quais estratégias? Quais competências? (2nd.ed.). Porto Alegre: Artmed.

Pontes júnior, J. de, \& Tálamo, M. de F. G. M. (2009, May/August). Alfabetização Digital: proposição de parâmetros metodológicos em competência informacional. Informaçãoe Sociedade: Estudos, 19 (2). Retrieved from http://biblioteca.idbrasil.gov.br/publicacoes/literatura/alfabetizacao-digital-proposicao-de-parametros.

Portal Banco de Saúde. Retrieved from http://www.bancodesaude.com.br/. 


\section{Ð1010 Competência informacional como recurso emancipatório}

Reece, G.J. (2007). Critical thinking and cognitive transfer: implication for the development of online information literacy tutorials. ResearchStrategies, 20 (4), 482-493.

Sociedade Brasileira de Diabetes. Retrieved from http://www.diabetes.org.br

Sociedade Brasileira de Diabetes. (2007). Tratamento e acompanhamento do diabetes mellitus: Diretrizes da Sociedade Brasileira de Diabetes. Rio de Janeiro: Diagraphic.

Takahashi, T. (Org.). (2000). Sociedade da informação no Brasil: livro verde. Brasília:Ministério da Ciência e Tecnologia.

Torres, H. de C., Souza, E. R., Lima, M. H. M.,\&Bodstein, R. C. (2011). Intervenção educativa para o autocuidado de indíviduos com diabetes mellitus, 24 (4), 514-519. Retrieved from http://www.scielo.br/pdf/ape/v24n4/a11v24n4.pdf

Xiaomu, Z., Ping, S., Mengli, W., \& Du Weichun, C.(2008, June). Delphi Research on Information Literacy Competency Standards for Higher Education in Beijing, China.Chinese Librarianship: an International Electronic Journal. Retrieved from http://www.whiteclouds.com/ iclc/cliej/cl25ZSWD.htm

Zurkowski, P. G. (1974). Information services environment relationships and priorities. Washington D. C.: National Commission on libraries. 


\section{Dados das autoras}

Nadi Helena Presser

Graduação em Ciências Econômicas (1990), mestrado (1999) e doutorado (2005) em Engenharia de Produção pela Universidade Federal de Santa Catarina. Professora Adjunta, dedicação exclusiva, da Universidade Federal de Pernambuco, com atuação na graduaçaõ e no programa de pós-graduação stricto sensu. Líder do grupo de pesquisa Prospecção e Práxis em Gestão da Informação, certificado pela UFPE, estuda o fenômeno da informação enquanto objeto de gestão, tanto no âmbito das práticas adotadas como das suas prospectivas e possibilidades futuras. Desenvolve projeto de pesquisa ná área de gestão acadêmica e competência informacional. Atua nos seguintes temas de interesse: gestão da informação, estudo do usuário e competência informacional, avaliação das atividades de informação, indicadores de qualidade e gestão acadêmica.

nadihelena@uol.com.br

Recebido - Received : :2012-08-30

Aceito - Accepted : :2012-12-30

1 Os percentuais, cujo somatório não alcança 100\%, representam a diferença dos entrevistados que não responderam determinadas perguntas. Por exemplo, a soma dos percentuais "quanto à faixa etária", totaliza 94\%. Por outro lado, os percentuais utilizados na tabela cuja soma ultrapassa $100 \%$ referem-se às perguntas que poderiam contar com mais de uma opção na sua resposta, como televisão, jornal impresso, etc.

(c) $\mathbf{E Y}$ New articles in this journal are licensed under a Creative Commons Attribution 3.0 United States License.

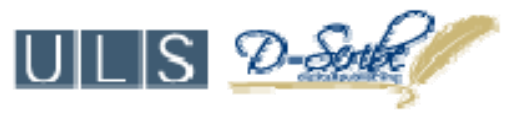

This journal is published by the University Library System of the University of Pittsburgh as part of its D-Scribe Digital Publishing Program and is cosponsored by the University of Pittsburgh Press. 